\title{
ASSOCIAÇÃO DE ESCLEROSE SISTÊMICA E CÂNCER DE COLO DE ÚTERO: RELATO DE CASO
}

\author{
Herica Cristiani Barra de Souza1, ${ }^{1}$, Clodoaldo Carvalho do Nascimento Neto ${ }^{1}$ \\ 1.Hospital de Clínicas Doutor Alberto Lima, Macapá (AP), Brasil. \\ *Autora correspondente: drahericabarra@gmail.com
}

\section{INTRODUÇÃO}

A esclerose sistêmica é um tipo de doença reumática que acomete o tecido conjuntivo, através de mecanismo autoimune, determinando principalmente alterações cutâneas, como espessamento cutâneo de extremidades distais, esclerodactilia e microstomia. Em alguns casos raros, pode ocorrer em associação com determinados tipos de câncer, manifestando-se como uma síndrome paraneoplásica.

\section{RELATO DE CASO}

M.D.S.C., sexo feminino, 61 anos, iniciou há 1 ano quadro de espessamento cutâneo, inicialmente nas mãos e nos pés, com progressão posterior para a região proximal dos membros e tronco, associado a prurido. Tinha diagnóstico de câncer de colo uterino há 2 meses, recebendo indicação de cuidados paliativos exclusivos devido ao estágio avançado da doença. Ao exame físico apresentava espessamento cutâneo difuso, esclerodactilia, microstomia e petéquias nas pontas dos dedos das mãos e dos pés. Os exames laboratoriais evidenciaram FAN de 1:640, anti-SCL 70 reagente (240,0 U/mL) e anticentrômero não reagente. Tomografia computadorizada (TC) de crânio foi normal; TC de tórax mostrou derrame pleural bilateral, linfonodos axilares aumentados em dimensões e número à esquerda, e coleção de gás na parede lateral do hemitórax esquerdo; TC de abdômen evidenciou lesão expansiva ao nível de colo e corpo uterinos, que se estendia para parede posterior da bexiga urinária e a parede anterior do reto.

\section{CONCLUSÃO}

Malignidades previamente existentes algumas vezes induzem sintomas iguais aos de doenças reumatológicas autoimunes, como a esclerose sistêmica, que podem ocorrer como uma síndrome paraneoplásica. Dependendo do tempo do início e da evolução desses sintomas e sua relação com o tempo do diagnóstico e evolução da neoplasia, as alterações neoplásicas tanto podem ser uma complicação tardia da doença reumatológica quanto podem induzir a síndromes paraneoplásicas reumáticas, como esclerose sistêmica, conforme descrito no presente relato de caso. Os fatores envolvidos em sua patogênese incluem hormônios, peptídeos, anticorpos, linfócitos citotóxicos e mediadores autócrinos e parácrinos, e não estão relacionados à invasão direta do tumor ou da metástase, como ocorre nas neoplasias. Dadas as raras, porém, fortes evidências encontradas na literatura a favor da associação entre esclerose sistêmica e neoplasias, uma possível relação entre ambas, inclusive do ponto vista de causalidade, nunca deve ser descartada.

\section{PALAVRAS-CHAVE}

Esclerose sistêmica, Câncer de colo uterino, Paraneoplasia. 